\title{
O rompimento do mineroduto em Santo Antônio do Grama/MG: impactos socioambientais na perspectiva da mídia nacional
}

The rupture of the ore slurry pipeline in Santo Antônio do Grama/MG: socio environmentals from the perspective of the national media

La ruptura del mineroducto em Santo Antônio do Grama/MG: impactos sociales y ambientales desde la perspectiva de los medios de comunicación nacionales

Letícia Dimas de Melo

ORCID: https://orcid.org/0000-0002-5497-6354 Universidade do Estado de Minas Gerais, Brasil E-mail: leticia.ddm@hotmail.com

Cláudia Duarte da Conceição

ORCID: https://orcid.org/0000-0002-0227-5046 Universidade do Estado de Minas Gerais, Brasil E-mail: claudia.conceicao@uemg.br

José Alves Ferreira Neto

ORCID: https://orcid.org/0000-0002-0597-8716 Universidade do Estado de Minas Gerais, Brasil E-mail: jose.neto@uemg.br Júnia Soares Alexandrino ORCID: https://orcid.org/0000-0002-6387-5491 Universidade do Estado de Minas Gerais, Brasil E-mail: junia.alexandrino@uemg.br Jussara Aparecida de Oliveira Cotta ORCID: https://orcid.org/0000-0001-6914-1176 Universidade do Estado de Minas Gerais, Brasil E-mail: jussara.cotta@uemg.br

\begin{abstract}
Resumo
É inegável a importância da atividade mineira para a economia do país. Contudo, um empreendimento mineiro traz intrínseco à sua atividade a alteração do meio ambiente onde se instala. Para gerenciar estes impactos e garantir que medidas compensatórias sejam aplicadas por parte da mineradora, o governo, criou um procedimento de licenciamento ambiental. O mineroduto sistema Minas-Rio, o maior do mundo, teve processos de solicitação de licenças polêmicos e cheio de imbróglios junto ao Ministério Público Federal. Entretanto, contando com a boa vontade política dos estados de Minas Gerais e do Rio de Janeiro, obteve não apenas as licenças autorizativas, mas também, benefícios de incentivo fiscal e o título de utilidade pública. Em 2018, com menos de quatro anos de operação, a mineradora Anglo American administradora do sistema, registrou duas ocorrências de rompimento do mineroduto, que acumularam 474 toneladas de polpa de minério de ferro no ribeirão Santo Antônio. Esta pesquisa teve como objetivo avaliar os principais impactos socioambientais causados pelo rompimento do mineroduto MinasRio sob a ótica da mídia e, para tanto, buscou elucidar quais foram esses principais impactos e quais foram as principais notícias pós-acidente. Foram realizadas pesquisas nos principais meios de comunicação do país, além de pesquisas bibliográficas em trabalhos científicos. Como resultado do estudo, pode-se afirmar que o impacto socioambiental decorrente do mineroduto Minas-Rio está muito além dos episódios de rompimento ocorridos em março de 2018 e que o poder econômico foi colocado acima dos deveres com o meio ambiente.
\end{abstract}

Palavras-chave: Mineroduto; Licença Ambiental; Impacto ambiental.

\begin{abstract}
The mining activity plays a vital role to the economy of a country. However, inherent to its activity, a mining company causes environmental alterations where it is installed. To manage these impacts and assure that mining companies are taking compensatory measures, the government has created a system of environmental licensing. Minas-Rio ore slurry pipeline system, the largest of the world, had a controversial and complicated process of requesting licenses from the Federal Public Ministry. Nevertheless, through political willingness of Minas Gerais and Rio de Janeiro states, obtained approval permits, as well as tax incentive benefits and the public utility title. In 2018, with less than four years of operation, Anglo American mining company, manager of the system, had reported two occurrences of ore slurry pipeline rupture. It spiled 474 tons of iron ore slurry into the Santo Antônio do Grama River.
\end{abstract}


This paper aimed to evaluate the main socio-environmental impacts caused by the rupture of the Minas-Rio ore pipeline from point of view of media. To achieve this, have sought to elucidate the main impacts and the main postaccident news. Research was conducted in the main media of the country, as well as bibliographic search in case studies, thesis and articles. Findings of this study, indicate that socio-environmental impact, arising from the MinasRio ore slurry pipeline, is well beyond the rupture episodes occurred in March 2018. Also, the results show that economic power was placed above duties towards the environment.

Keywords: Ore slurry pipeline; Ambiental license; Environmental impacts.

\section{Resumen}

Es innegable la importancia de la actividad mineral para la economía del país. Sin embargo, una empresa minera trae intrínseca a su actividad la alteración del entorno donde se instala. Para gestionar eses impactos e garantir que medidas compensatorias sean aplicado por la empresa minera, el gobierno creó un procedimiento de licencias ambientales. Lo mineroducto sistema Minas-Rio, el más grande del mundo, tuvo procesos de solicitud de licencias controvertidas y llenas de embrollos junto con el Ministerio Público Federal. Sin embargo, contando con la buena voluntad política de los estados de Minas Gerais y de Rio de Janeiro, recibió no solo las licencias de autorización, pero también, beneficios de incentivos fiscales y el título de utilidad pública. En 2018, con menos de cuatro años de operación, la empresa minera Anglo American administradora del sistema, registró dos ocurrencias de ruptura de lo mineroducto, que acumulan 474 toneladas de pulpa de mineral de Hierro en el arroyo Santo Antônio. Esta investigación tuvo como objetivo evaluar los principales impactos sociales y ambientales causados por la ruptura de lo mineroducto Minas-Rio desde la perspectiva de los medios y, con ese fin, buscó de dilucidar cuáles fueron estos impactos principales y cuáles fueron las principales noticias posteriores al accidente. Se realizaron encuestas en los principales medios del país, además, investigación bibliográfica en estudios de casos, tesis y artículos. Como resultado del estudio, se puede afirmar que el impacto social y ambiental derivado del mineroducto Minas-Rio está mucho más allá de los episodios de ruptura que ocurrieron em marzo de 2018 y que el poder económico se colocó por encima de los deberes con el medio ambiente.

Palabras clave: Mineroducto; Licencia ambiental; Impacto ambiental.

\section{Introdução}

A mineração é uma atividade extremamente importante para o equilíbrio da economia do Brasil. Ela é responsável por quase 5\% do Produto Interno Bruto (PIB) nacional e mantém estabilidade das balanças comerciais, já que é responsável pelos superávits de exportação. Dentre os minérios exportados, o minério de ferro é a commodity que mais se destaca, devido sua qualidade e disponibilidade no território brasileiro (Instituto Minere, 2018).

No caminho da exportação do minério, os portos são o ponto final, entretanto, são muitos os obstáculos para que o minério chegue ao seu destino. As empresas extrativas, de forma geral, estão situadas em locais com pouca ou nenhuma infraestrutura. Por isso, a ferrovia costuma ser o modo mais atrativo para se realizar essa logística.

Outro meio para execução da logística de escoamento do minério de ferro são os minerodutos, que são basicamente sistemas de tubulação que transportam polpas de minério de ferro por longas distâncias. No Brasil, o maior mineroduto em operação é o Sistema Minas-Rio da empresa Anglo American, que, com extensão de 529 quilômetros (km) apresenta capacidade de produção para 26,5 milhões de toneladas de minério por ano (Anglo American, 2015).

O sistema de mineroduto apresenta vantagens significativas. Desde o baixo consumo energético, até fatores ambientais como a mitigação de ruídos, a não emissão de dióxido de carbono e minimização de emissão de poluentes. Contudo, a necessidade de realizar a supressão vegetal e terraplanagem em alguns pontos de passagem da tubulação, a necessidade de desocupação de famílias em áreas onde é instalado o sistema, o alto consumo de água para fluidez da polpa do minério, além do risco de rompimento ao longo do sistema de tubulação, tornam o sistema polêmico e controverso aos interesses socioambientais. Ressalta-se a importância da água neste processo e também para a qualidade de vida humana e animal, segundo Reis et. al. (2019), acidentes ligados à mineração podem ocasionar na disponibilização de sedimentos contaminados, degradando com maior impacto ecossistemas aquáticos.

Neste contexto, este trabalho destacou dois episódios de rompimento no sistema de mineroduto Minas-Rio, ocorridos em março de 2018 no município de Santo Antônio do Grama e, sua repercussão nos meios de comunicação para responder a 
seguinte problemática: quais foram os impactos socioambientais causados em decorrência do rompimento do mineroduto na perspectiva dos meios de comunicação nacional?

Esta pesquisa teve como objetivo geral avaliar os principais impactos socioambientais causados, sob a perspectiva dos meios de comunicação, no rompimento do mineroduto Minas-Rio. Para tanto expôs-se os seguintes objetivos específicos: a) quais foram os principais impactos socioambientais provocados pelo primeiro rompimento do mineroduto, segundo os meios de comunicação; b) quais foram os principais impactos socioambientais provocados pelo segundo rompimento do mineroduto, de acordo com os meios de comunicação; c) quais as principais notícias pós-acidente.

Metodologicamente esta pesquisa caracterizou-se como aplicada, de enfoque qualitativo, exploratória, desenvolvida através de um estudo de caso.

\section{2. Área de Estudo}

O município de Santo Antônio do Grama, conforme ilustrado na Figura 1, está localizado na Zona da Mata de Minas Gerais, na microrregião de Ponte Nova. A cidade possui área de 130,213 Km² e está geograficamente localizada nas coordenadas de latitude $20^{\circ} 18$ '52" S e longitude 42 36’31" O (IBGE, 2010). De acordo com a estimativa da população realizada pelo IBGE (2021), Santo Antônio do Grama possui população estimada de 3.861 habitantes (IBGE, 2021).

Figura 1 - Mapa da Mesorregião Zona da Mata e Microrregião Ponte Nova (MG).

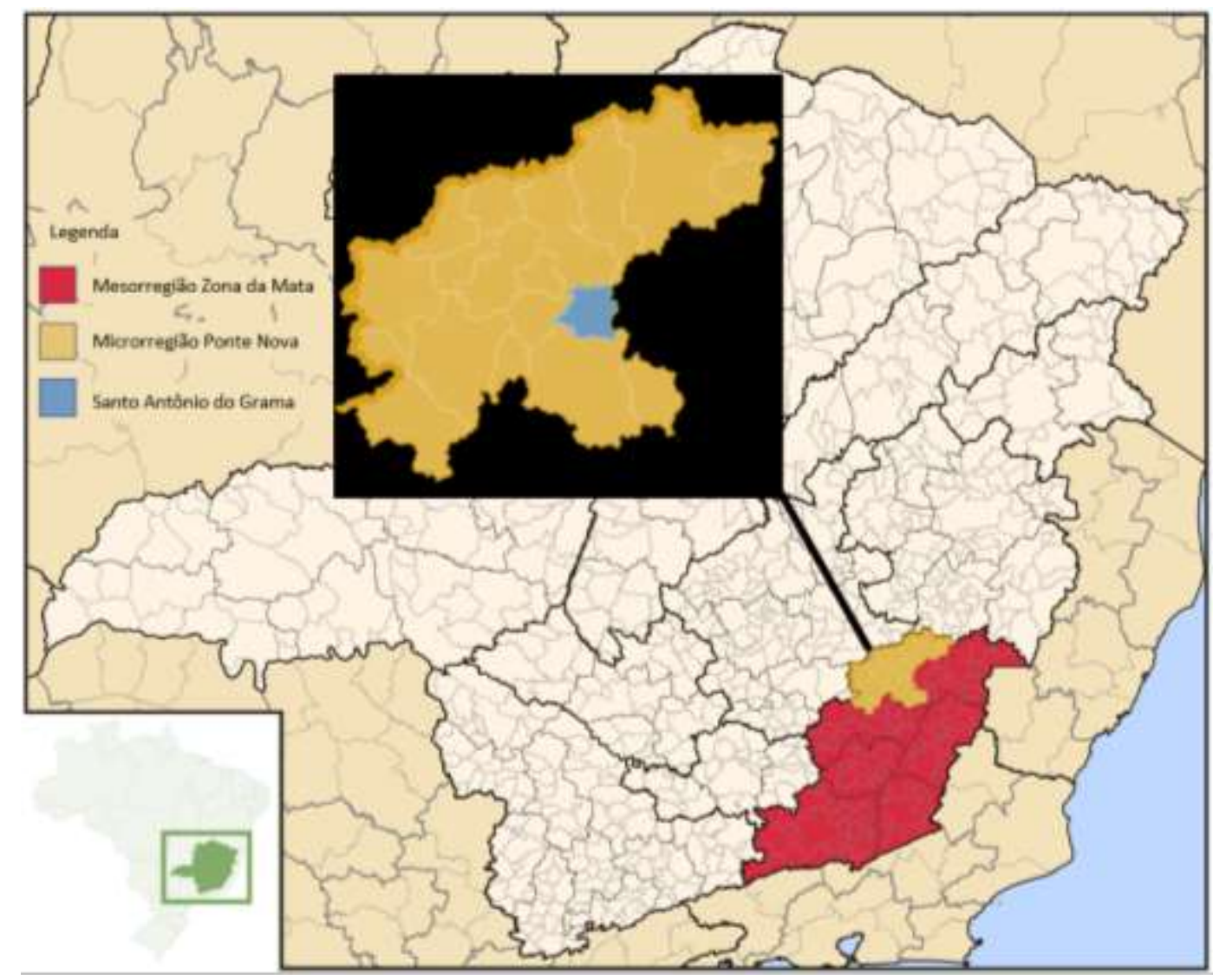

Fonte: Formatação adaptada pelos autores, baseado em IBGE, 2021.

A empresa Anglo American é uma empresa multinacional de mineração diversificada. Com sede em Londres, no Reino Unido, foi fundada em 1917. No Brasil, com operações instaladas desde 1973, seu escritório administrativo está situado na capital mineira, Belo Horizonte. Seu portfólio apresenta produção de carvão, cobre, níquel, platina, Diamante, minério de 
Ferro e Manganês (Anglo American, 2008). Seu principal investimento no Brasil é o sistema de mineroduto Minas-Rio gerenciado pela Unidade de Negócio Minério de Ferro Brasil, a Anglo Ferrous Brazil. Segundo Magalhães Júnior et al. (2020), apesar de a instalação de minerodutos poder favorecer impactos, desastres e conflitos socioambientais, os mesmos representam, em termos de logística, modais de transporte dentre os mais eficientes.

O Sistema de mineroduto Minas-Rio, é o maior mineroduto do mundo com $529 \mathrm{~km}$ de extensão, conectando a mina Sapo-Ferrugem no município de Conceição do Mato Dentro em Minas Gerais, até o porto de Açu no município de São João da Barra no estado do Rio de Janeiro (Anglo American, 2015). A primeira Licença Prévia (LP) foi solicitada pela empresa em meados de 2006 e, em meio a muita polêmica, falta de clareza nas informações e muita vontade política dos estados de Minas Gerais e do Rio de Janeiro, a Licença de Instalação (LI) foi autorizada e o empreendimento seguiu com o projeto. Sua primeira Licença de Operação (LO) foi concedida pelo Ibama em outubro de 2014 (CETEM, 2016). Apenas 04 (quatro) anos após o início das operações duas ocorrências de vazamento aconteceram dentro da área do mesmo município, Santo Antônio do Grama, projetando polpa de minério no ribeirão Santo Antônio (G1 MG, 2018).

\section{A Importância Econômica do Minério de Ferro e os Riscos de Impactos Ambientais}

A extração mineral é uma importante força motriz na economia do Brasil. Somente o setor de extração mineral mantem 581.478 postos de trabalho, destes um total de 31,6\% estão alocados no estado de Minas Gerais (ANM, 2018). O Brasil está entre os principais produtores de minério de ferro no mundo. As três maiores empresas do ramo têm instalações no país: Vale S. A., Anglo American, Rio Tinto e BHP Billiton. O minério de ferro produzido, é comercializado observando além de teores, sua granulometria, classificados em: lump ore (granulado), sínter feed (finos para sínter) e, pellet feed (finos para pelotas) (Carvalho et al., 2013).

\subsection{Impactos Ambientais e ações para redução desses impactos}

A extração do minério de ferro pelas empresas extrativas, por questões técnicas, é, em sua maioria, realizada a céu aberto causando imensa transformação visual no ambiente onde se instala, por isso, mesmo ofertando benefícios, provoca rejeição e discriminação da sociedade. Esse sentimento se agrava quando, em muitas situações, o cuidado com o meio ambiente é deixado de lado em nome do desenvolvimento econômico (Souza et al., 2010, apud Costa, 2016). O Conselho Nacional de Meio Ambiente (CONAMA) considera como impacto ambiental, por meio da Resolução 001/86, qualquer alteração no meio ambiente resultada de atividades humanas (Brasil, 2012). Consonante, Moreira (1997), traz que impacto ambiental é qualquer alteração no ambiente, realizada pelo homem, que exceda sua capacidade de absorção. De igual forma Silveira (2006) define impacto ambiental como sendo um conjunto de consequências que uma nova obra, pública ou privada, possa causar no ambiente. Para apresentar maior clareza à população sobre os possíveis impactos ambientais de um novo empreendimento, bem como as vantagens e desvantagens do negócio à sociedade, o CONAMA, através da Resolução 001/86, tornou obrigatória a Avaliação de Impactos Ambientais (AIA) por meio do Estudo de Impacto Ambiental (EIA) e o Relatório de Impacto Ambiental (RIMA) por parte da empresa interessada (Brasil, 2012). O EIA deve ser elaborado por equipe multidisciplinar e conter informações técnicas e detalhadas sobre o empreendimento. Ele deve conter no mínimo: a) o diagnóstico ambiental da área de influência do projeto; b) a análise dos impactos ambientais do projeto e de suas alternativas; c) a definição das medidas mitigadoras dos impactos negativos; d) a elaboração do programa de acompanhamento e monitoramento da área de influência do projeto. Já o RIMA, deve se tornar um documento de domínio público, ou seja, essas informações devem ser convertidas em uma linguagem acessível à população, com figuras, mapas, quadros e gráficos, ofertando boa comunicação visual (PNLA, 2019). Esses documentos são exigidos como condicionantes para a aprovação da licença ambiental. 
A fim de constituir mecanismos de gestão e controle, são exigidos de todos os empreendimentos que possam causar impactos ambientais, tais como extração e tratamento de minérios, indústria de produtos minerais não metálicos, indústria metalúrgica, indústria mecânica, indústria de material de transporte, indústria de madeira, indústria de papel e celulose, indústria de borracha, indústria química, dentre outras, licenças ambientais a serem emitidas pelos órgãos governamentais competentes (FIRJAN, 2004). Ainda de acordo com a FIRJAN (2004), a licença ambiental tem prazo de validade préestabelecido e preconiza regras, condições, restrições e medidas de controle a serem empregadas pela empresa requerente da licença. As licenças são divididas em três tipos, conforme indicado na Tabela 1.

Tabela 1 - Tipos de Licenciamento Ambiental.

\begin{tabular}{cc}
\hline Tipo de Licença & Descrição \\
\hline Licença Prévia (LP) & $\begin{array}{c}\text { Nesta etapa o órgão avalia a partir da localização, a viabilidade ambiental do empreendimento, e } \\
\text { definido os requisitos de controle ambiental. Pode ser requerido o AIA. }\end{array}$ \\
\hline Licença de Instalação (LI) & $\begin{array}{c}\text { Uma vez detalhado o projeto inicial e definidas as medidas de proteção ambiental, deve ser } \\
\text { requerida a Licença de Instalação (LI), cuja concessão autoriza o início da construção do } \\
\text { empreendimento e a instalação dos equipamentos. }\end{array}$ \\
\hline Licença de Operação (LO) & $\begin{array}{c}\text { A Licença de Operação autoriza o funcionamento do empreendimento. Essa deve ser requerida } \\
\text { quando a empresa estiver edificada e após a verificação da eficácia das medidas de controle } \\
\text { ambiental estabelecidas nas condicionantes das licenças anteriores }\end{array}$ \\
\hline
\end{tabular}

Fonte: Elaborado pelos autores, baseado em FIRJAN (2004).

Para Sánchez (1994), qualquer empresa só terá um bom programa de gerenciamento ambiental se possuir um bom plano de ação para as emergências ambientais, como por exemplo, acidentes industriais e vazamentos de produtos ou insumos, tanto dentro quanto fora do polo industrial. Ainda de acordo com Sánchez (1994), só basta um acidente para comprometer a imagem de uma empresa, que geralmente leva muito tempo para ser construída. Daí a importância de a sustentabilidade ser algo inerente ao desenvolvimento da mineração, segundo Ferreira (2020), o desenvolvimento sustentável representa um pilar na sociedade moderna, e essa sustentabilidade é mantida por um tripé formado pelos fatores sociais, econômicos e ambientais

\subsection{Sistemas de Mineroduto Minas-Rio}

O mineroduto Minas-Rio compreende uma das três estruturas do Projeto Minas-Rio das empresas MMX e Anglo American que se iniciou em 2006. Em 2008, o controle acionário do projeto foi assumido pela Anglo American, que passou a ser denominado Anglo Ferrous Minas-Rio Mineração (Anglo American, 2008). Classificado como o maior mineroduto do mundo, com seus 529 km, o sistema transporta o minério lavrado na mina Sapo-Ferrugem no município de Conceição do Mato Dentro (MG), beneficiado na usina localizada no município mineiro de Alvorada 17 até o porto de Açu localizado na cidade fluminense São João da Barra (Borges, 2018), conforme apresentado na Figura 2. 
Figura 2 - Sistema Mineroduto Minas-Rio.

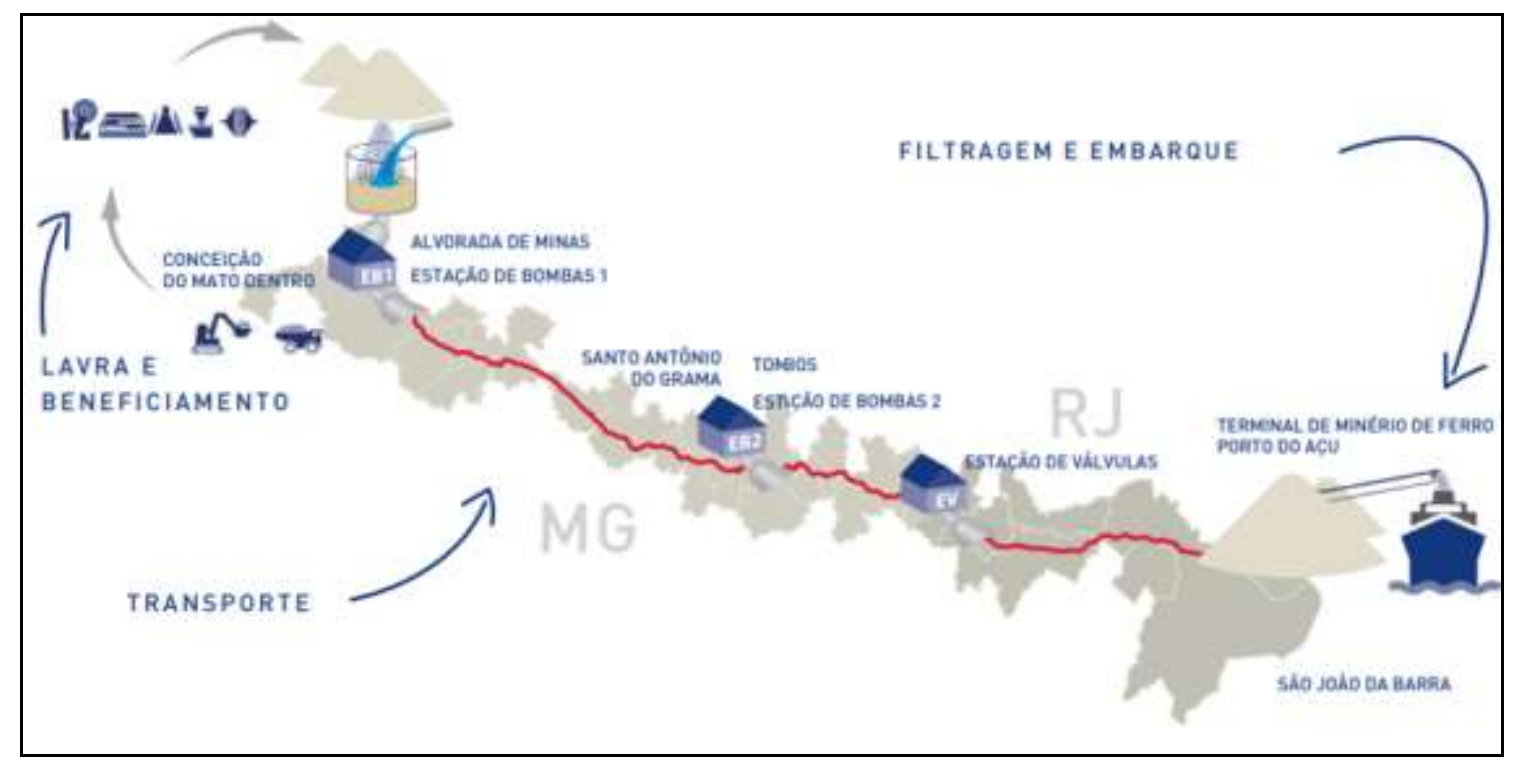

Fonte: Anglo American (2015).

A tubulação foi enterrada $75 \mathrm{~cm}$ abaixo do solo e a terra recomposta para não causar impacto visual, contudo, os donos da terra por onde passa os dutos, não podem cultivar nada em uma faixa de 30 metros em torno da linha traçada (CETEM, 2016). Ainda de acordo com o CETEM (2016), houve um imbróglio muito grande envolvendo as licenças ambientais do projeto, já que, por interesses políticos dos estados de Minas Gerais e do Rio de Janeiro, as licenças foram emitidas mesmo sendo apontadas lacunas e inviabilidade nos estudos de impactos ambientais. As licenças foram emitidas sem nem mesmo conhecer o traçado do mineroduto. O Ministério Público Federal (MPF) chegou a ajuizar ações contra o empreendimento, mas não intimidou os Estados na emissão das licenças autorizativas. Por meio de um decreto, o Estado de Minas Gerais chegou a declarar o projeto como de utilidade pública para justificar a supressão vegetal em área de Mata Atlântica, bem como autorizar a desapropriação de 752 propriedades em 25 municípios em favor da Anglo American. Consonante ao Estado de Minas Gerais, o Estado do Rio de Janeiro avalizou com decreto semelhante à desapropriação de 369 propriedades em 07 (sete) municípios. O governo federal, concedeu ainda, incentivos fiscais à empresa extrativa, enquadrandoa no Regime Especial de Incentivos para o Desenvolvimento da Infraestrutura (Reidi), que prevê isenção de alguns tributos federais durante cinco anos. Além dos impactos sobre o meio ambiente e sobre a população local há ainda a questão dos recursos hídricos. É necessária uma quantidade considerável de água para possibilitar a fluidez da polpa na tubulação (em torno de $3.123 \mathrm{~m}^{3} / \mathrm{h}$ ) a ser retirada principalmente do Rio do Peixe. A licença concedida pelo Instituto Mineiro de Gestão de Águas (Igam) outorga a captação de 2,5 milhões de litros de água por hora, o suficiente para abastecer uma cidade com 396 mil habitantes (CETEM, 2016). As contrapartidas para compensação ambiental foram julgadas incipientes pelo MPF, haja vista a extensão do projeto e seus significativos impactos. Contudo, em setembro de 2014, o Instituto Brasileiro de Meio Ambiente e dos Recursos Renováveis (Ibama) concedeu liberação para operação (LO) para o mineroduto (CETEM, 2016). De acordo com o CETEM (2016), logo no seu primeiro carregamento de testes, ainda em 2014, houve mortandade de peixes no córrego Passa Sete em Conceição do Mato Dentro. Mesmo tendo conhecimento da mortandade, o Ibama não instaurou investigação para esclarecer as causas. No dia 12 de março de 2018, a tubulação do mineroduto se rompeu no município mineiro Santo Antônio do Grama atingindo o ribeirão Santo Antônio. O minério despejado, 300 toneladas de polpa, no ribeirão provocou a interrupção do abastecimento de água na cidade. Menos de 20 dias após este rompimento, houve um segundo incidente no mesmo município, despejando novamente polpa de minério, 174 toneladas de polpa, no ribeirão Santo Antônio. Após o segundo vazamento, o Ibama suspendeu a LO do mineroduto (G1 MG, 2018) 


\section{Metodologia}

Este estudo, de natureza qualitativa, se desdobrará em quatro componentes principais: levantamento bibliográfico, levantamento de dados secundários (estudo de caso), pesquisa qualitativa (através de revisão bibliográfica) e discussão dos resultados. É um trabalho que se caracteriza como pesquisa básica. Segundo Lakatos e Marconi (2012), a pesquisa básica tem como principal atribuição gerar novos conhecimentos a partir de análises fundamentais de fenômenos e procedimentos, no caso, os impactos socioambientais causados pelo rompimento do mineroduto pertencente à empresa Anglo American, ocorrido em março de 2018, no município de Santo Antônio do Grama, em Minas Gerais. Através do modelo de checklist criado por Costa (2016), foram selecionados quatro exemplares de cada meio de comunicação e identificados os principais impactos positivos e negativos. Posteriormente, foram analisados e avaliados de acordo com a matriz de avaliação de impactos ambientais. De acordo com os objetivos, esta pesquisa inicia-se com uma pesquisa exploratória, pois, segundo Lakatos e Marconi (2012), esta constitui o primeiro estágio de toda pesquisa científica. Segundo Gil (2012), a pesquisa exploratória visa possibilitar um maior conhecimento do problema e tem o intuito de construir hipóteses para o mesmo. A hipótese apresentada para este projeto de pesquisa gira em torno dos cuidados que empresas extrativas e governos devem ter para que tragédias ambientais e sociais sejam evitadas, visando um desenvolvimento econômico consciente sem danos ambientais e que esteja dentro das normas estabelecidas pelos órgãos ambientais responsáveis. Quanto aos procedimentos técnicos, o trabalho utilizou os procedimentos de uma pesquisa bibliográfica. A pesquisa bibliográfica, conforme Cervo et.al. (2012), é o meio mais adequado quando se deseja obter informações científicas, pois é desenvolvida a partir de livros ou artigos já elaborados e publicados sobre o tema. Portanto, permite ao investigador uma cobertura mais ampla do tema em estudo. No caso deste trabalho investigativo, foram reunidos conteúdos divulgados em jornais, revistas e sites a respeito do acidente ocorrido, a fim de estabelecer em um só local, informações completas sobre o caso. Inicialmente, foi realizada a coleta de informações publicadas pela mídia falada e escrita, desde o dia do fato até os dias atuais. Posteriormente, seguiu-se a qualificação e organização desse material para que as informações fossem reunidas e explicitadas nesta obra.

Tabela 2 - Principais artigos para identificação dos impactos ambientais.

\begin{tabular}{|c|c|c|}
\hline Tipo de Mídia/ Documento & Citação & Total de Matérias \\
\hline \multirow[t]{4}{*}{ Telejornais } & MG TV & \multirow[t]{4}{*}{4} \\
\hline & MG RECORD & \\
\hline & TV BRASIL & \\
\hline & TV EDUCAR & \\
\hline \multirow{4}{*}{$\begin{array}{c}\text { Sites } \\
\text { (Jornais e Revistas) }\end{array}$} & em.com.br & \multirow[t]{4}{*}{4} \\
\hline & revistamineracao.com.br & \\
\hline & exame.abril.com.br & \\
\hline & istoe.com.br & \\
\hline Comunicado & SEMAD (2018) & \multirow[t]{2}{*}{02} \\
\hline Relatórios & Minas Gerais (2018) & \\
\hline TOTAL & & 10 \\
\hline
\end{tabular}

Fonte: Autores (2019).

\section{Resultados e Discussões}

A seguir serão relatados e identificados os principais impactos socioambientais provocados pelo primeiro e segundo rompimento do mineroduto da Anglo American, segundo a Mídia Falada e Escrita. 


\subsection{Primeiro Rompimento do Mineroduto da Anglo American}

Mídias como MG TV, MG RECORD, Estado de Minas, Revista EXAME, Revista Mineração e Revista ISTO É, trouxeram os seguintes fatos:

No dia 12 de março de 2018, às 07:42 horas da manhã, ocorreu um vazamento no mineroduto Minas-Rio, operada pela Anglo Ferrous Brazil. O ponto de vazamento foi no município de Santo Antônio do Grama em Minas Gerais e durou aproximadamente 25 minutos, liberando 300 toneladas de polpa de minério de ferro no Ribeirão Santo Antônio. A Figura 3 ilustra como foi a projeção dessa polpa.

Figura 3 - Projeção de polpa de minério de ferro no ribeirão Santo Antônio.

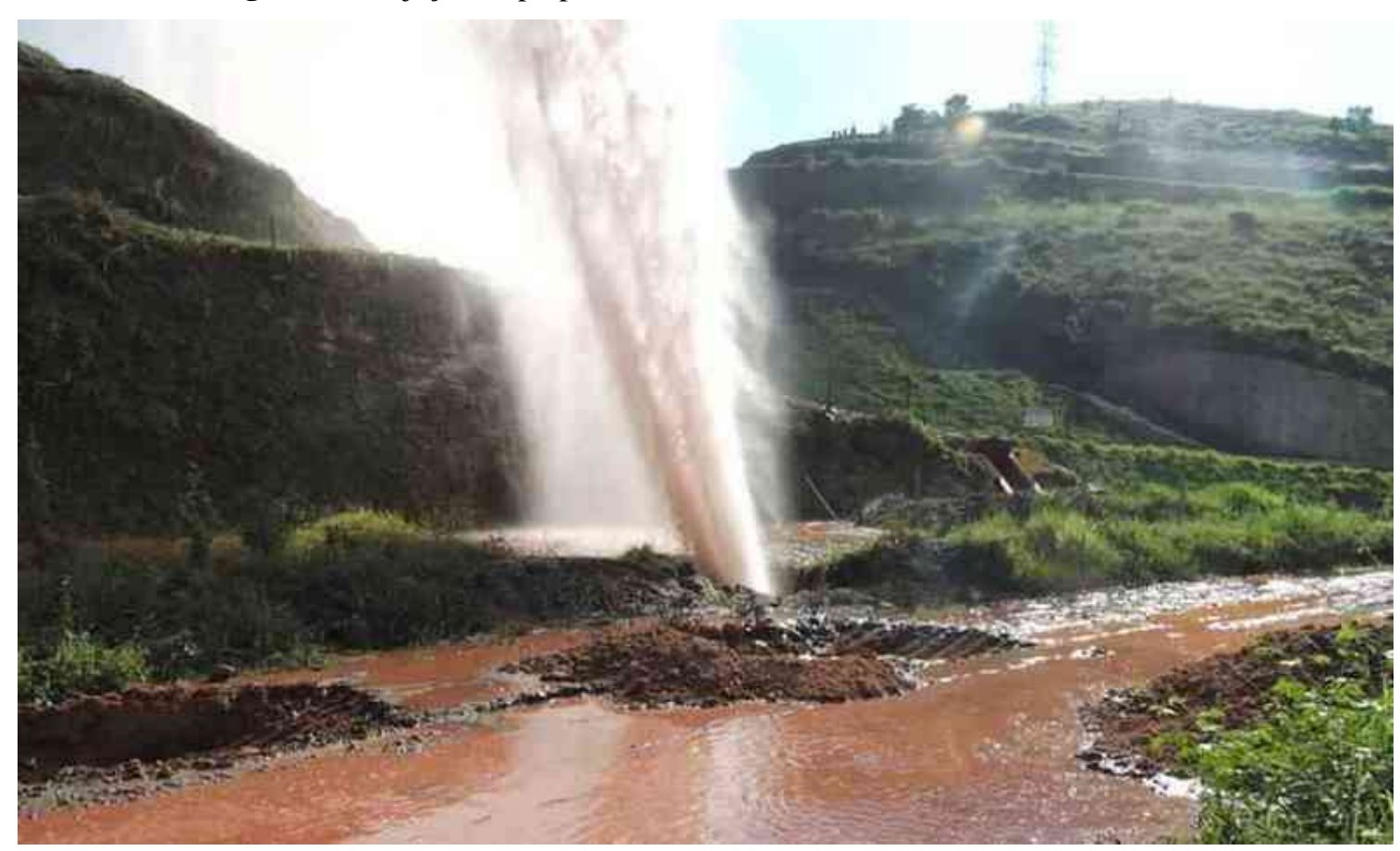

Fonte: Estado de Minas (2018).

Este fato provocou a interrupção de captação de água e consequente abastecimento na cidade. Como medida compensatória a mineradora disponibilizou caminhões pipa para atender aos moradores da cidade.

A Secretaria de Meio Ambiente e Desenvolvimento Sustentável de Minas Gerais (Semad) recebeu um comunicado da Anglo American acerca do rompimento. O Ibama, que concedeu LO com validade até 2021, também foi comunicado, contudo, não se cogitou a suspensão da licença. O órgão apenas encaminhou uma equipe para vistoria dos impactos ambientais causados para dirimir sobre possíveis sanções administrativas.

O telejornal EDUCAR, foi ao local e enfatizou quanto as necessidades básicas da população. Foi encontrado no momento, relato a respeito da falta de abastecimento de água que, após 14 horas, ainda não havia sido regularizado. Apesar de a Anglo American ter contratado caminhões-pipa para auxiliar no abastecimento de água na cidade, constatou-se um alto nível de turbidez dessa água, impedindo o uso pela população.

O jornal foi até o local de captação de água potável da COPASA, que fica distante do empreendimento e constatou que a água do ribeirão, mesmo após $14 \mathrm{~h}$ do rompimento, ainda apresentava com cor avermelhada. Contudo, a empresa afirmou que até o momento a polpa de minério não teria chegado ao Rio Casca, por causa das contenções feitas, informação essa, negada pelo Telejornal ao informar que rejeitos mais pesados se encontravam no leito do Ribeirão e rejeitos mais finos haviam se diluído na água e chegado ao Rio Casca. 
Quatro dias após o ocorrido, a Justiça deferiu, um pedido do Ministério Público de Minas Gerais (MPMG) em ação civil pública ajuizada contra a Anglo American Minério de Ferro Brasil e determinou a adoção de medidas emergenciais. A decisão judicial estabeleceu o bloqueio de $\mathrm{R} \$ 10$ milhões da mineradora.

Ressalta-se a falta de informação posterior ao impacto ambiental para esclarecimento dos fatos.

\subsection{Segundo Rompimento do Mineroduto da Anglo American}

Mídias como MG TV, MG RECORD, Estado de Minas e Revista Mineração, trouxeram os seguintes fatos a respeito do segundo rompimento:

No dia 29 de março às 18:55 horas da noite, apenas 17 dias após o primeiro rompimento do mineroduto Minas-Rio, o incidente voltou a se repetir. Desta vez o rompimento teve duração menor, de apenas 5 minutos, o suficiente para despejar 174 toneladas de polpa de minério de ferro no ribeirão Santo Antônio.

Desta vez, a população não sentiu o impacto no abastecimento da cidade pois desde o primeiro rompimento, a COPASA estava captando água do ribeirão Salgado, já que o ribeirão Santo Antônio ainda não havia se recuperado do primeiro incidente. $\mathrm{O}$ ribeirão afetado além de servir para abastecimento da população, também era utilizado para pesca e irrigação de plantações nas zonas urbana e rural.

O rompimento atingiu também uma fazenda, além do Ribeirão Santo Antônio. De acordo com o Ibama, fora as 174 toneladas de polpa de minério despejadas no curso d'água, 470 toneladas atingiram áreas do entorno.

A recorrência do incidente e falta de clareza nas informações por parte da mineradora causou insegurança e desconfiança nos moradores da região.

\subsection{Principais Notícias Pós-acidente de Acordo com a Mídia}

Os seguintes fatos foram reportados após o segundo rompimento:

Após o segundo rompimento em menos de 20 dias, o Ibama aplicou um efeito suspensivo na LO concedida à empresa. A mineradora Anglo American, acumulou na ocasião R\$ 197,6 milhões em multas em razão dos cinco autos emitidos pelo Ibama que totalizam R \$ 72,6 milhões somados aos R $\$ 125$ milhões pedidos pela Semad (Estado de Minas, 2018).

Além das sanções ambientais, a empresa acumulou prejuízos em função de produção. Com o primeiro rompimento, houve paralisação da produção para reparo no mineroduto e o estoque de minério que estava no porto compensou a paralisação. Com o segundo incidente em menos de 20 dias e, com a LO suspensa, a empresa não teve estoque no porto para cumprir sua agenda de exportação (G1 MG, 2018)

Os incidentes, resultaram no lançamento de 947 toneladas de minério de ferro em no município mineiro de Santo Antônio do Grama. O minério se espalhou por cerca de $11 \mathrm{~km}$ de extensão afetando a captação de água na cidade. Durante três dias, os moradores dependeram de caminhões-pipa da mineradora, até que uma nova adutora fosse instalada em outro córrego, o Salgado (G1 MG, 2018).

De acordo com o site de notícias G1, a licença ambiental do mineroduto Minas-Rio da Anglo American foi suspensa pelo Ibama após o segundo vazamento de polpa de minério (G1 MG, 2018).

A paralisação da empresa estendeu-se por 90 dias já que foi necessária uma avaliação em toda a extensão do mineroduto para que a LO fosse autorizada novamente. A empresa concedeu férias coletivas a seus empregados e falou-se em acordo para quebra dos contratos após esse período. No porto de Açu, os empregados também ficaram de férias coletivas e sem previsão de retorno (EM, 2018). 


\subsection{Impactos Identificados Através das Mídias Sociais}

A partir de análise das reportagens, documentos e depoimentos foram identificados impactos provocados pelo rompimento do Mineroduto, conforme apresentado na Tabela 3.

Na Tabela 4 estão descritas algumas medidas mitigatórias e compensatórias apresentadas pela empresa, para os impactos negativos causados em decorrência ao rompimento do mineroduto.

Tabela 3 - Matriz de Avaliação de Impactos causados pelos rompimentos do mineroduto Minas-Rio.

\section{IMPACTOS}

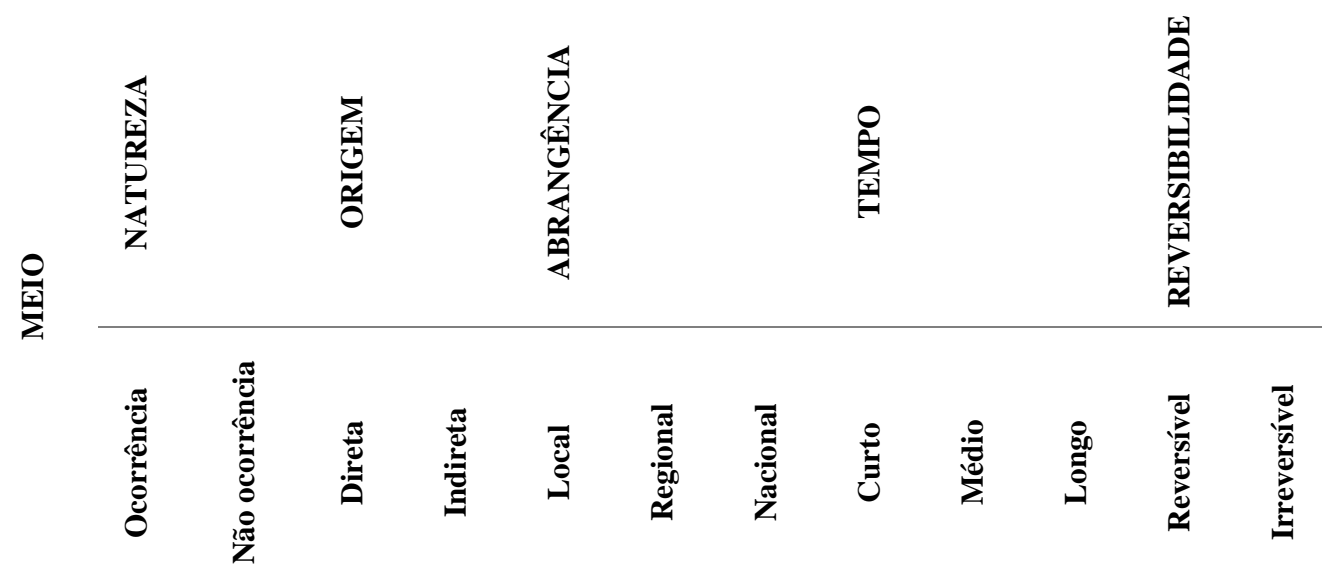

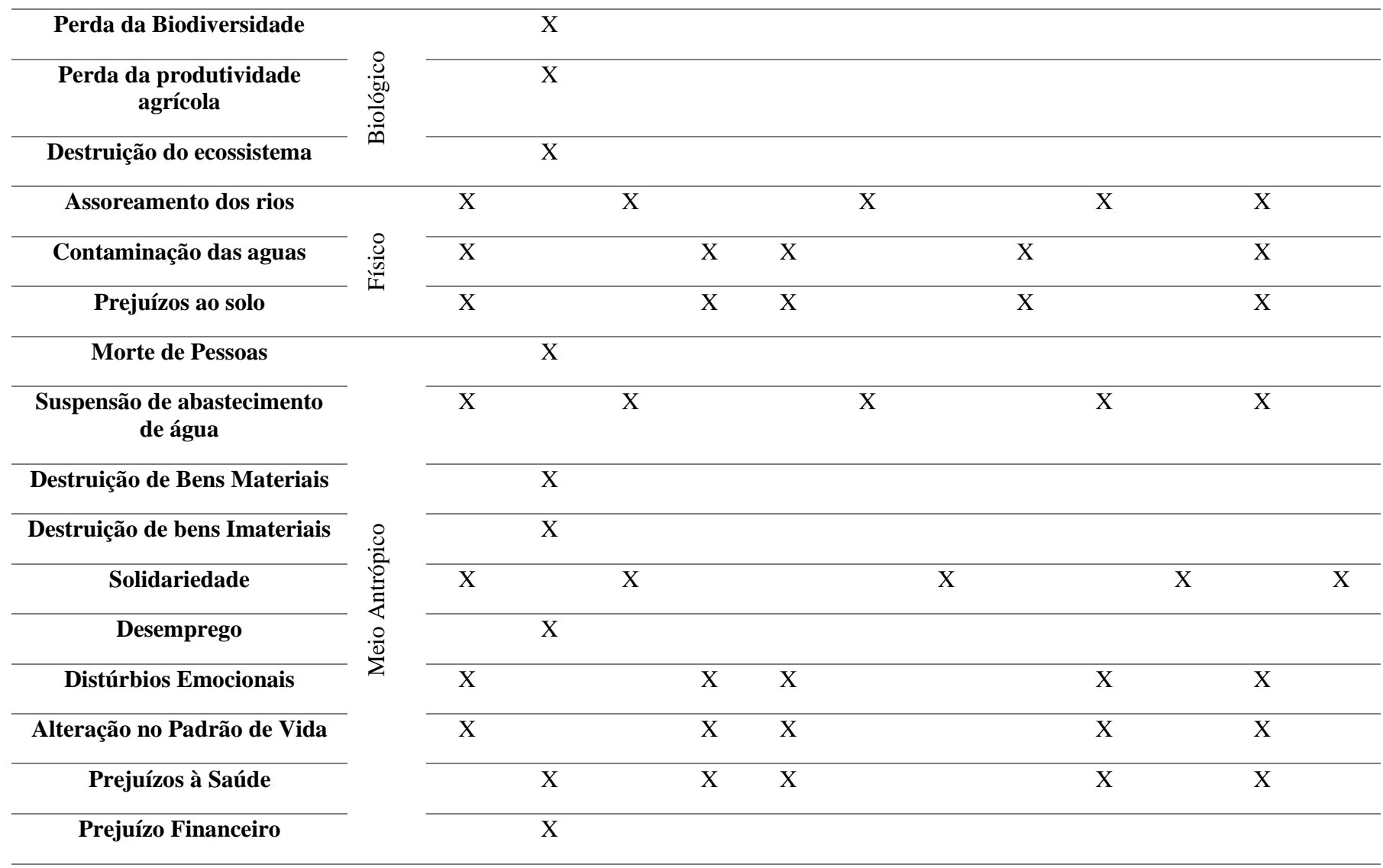

Fonte: Elaborado pelos autores, baseado em Costa (2016). 
Tabela 4 - Medidas mitigadoras e compensatórias para os impactos que foram identificados dentre os citados na Tabela 3, decorrentes do rompimento do mineroduto Minas-Rio

\begin{tabular}{|c|c|c|}
\hline \multirow[t]{2}{*}{ Impacto } & \multicolumn{2}{|c|}{ Alternativa } \\
\hline & Mitigatória & Compensatória \\
\hline Assoreamento dos Rios & $\begin{array}{c}\text { Fiscalizar e monitorar a aplicação das ações } \\
\text { previstas no relatório de impacto ambiental e no } \\
\text { plano de gestão ambiental. }\end{array}$ & $\begin{array}{l}\text { Planejar e propor métodos eficazes que reduzam } \\
\text { o assoreamento dos rios. }\end{array}$ \\
\hline Contaminação das Águas & $\begin{array}{l}\text { Fiscalizar, monitorar e obstruir o lançamento de } \\
\text { rejeito nos diferentes sistemas ambientais. }\end{array}$ & $\begin{array}{c}\text { Planejar e propor mediadas de tratamento da } \\
\text { água com constante monitoramento. }\end{array}$ \\
\hline Prejuízos ao Solo & $\begin{array}{l}\text { Fiscalizar, monitorar a disposição de rejeitos nos } \\
\text { sistemas ambientais. }\end{array}$ & $\begin{array}{l}\text { Implementar atividades que removam a poupa e } \\
\text { que promovam o controle de nutrientes no solo. }\end{array}$ \\
\hline Suspensão de Abastecimento de Água & $\begin{array}{l}\text { Implementar monitoramento das águas superficiais } \\
\text { e subterrâneas. }\end{array}$ & $\begin{array}{c}\text { Estabelecer mecanismos para normalizar o } \\
\text { fornecimento de água }\end{array}$ \\
\hline Disturbios Emocionais & $\begin{array}{l}\text { Contratar profissionais especializados para dar } \\
\text { assistência às famílias afetadas. }\end{array}$ & $\begin{array}{l}\text { Possibilitar o acompanhamento profissional das } \\
\text { famílias afetadas. }\end{array}$ \\
\hline Alteração no Padrão de Vida & $\begin{array}{l}\text { Suspender as atividades da mineradora até que seja } \\
\text { apresentado planos de contenção e compensação } \\
\text { causados pelo evento ocorrido. }\end{array}$ & $\begin{array}{c}\text { Fornecer o necessário aos moradores para que os } \\
\text { moradores afetados possam retomar seu padrão } \\
\text { de vida anterior. }\end{array}$ \\
\hline
\end{tabular}

Fonte: Elaborado pelos autores, baseado em Costa (2016).

Os impactos visualizados através da mídia mostram impactos em meio físico e antrópico conforme Tabela 3. Em meio físico observou-se o assoreamento dos córregos, contaminação das águas e prejuízos ao solo, provocados pela projeção de lama de minério de ferro. Em meio antrópico pode-se observar a suspensão do abastecimento de água e distúrbios emocionais, já que o segundo rompimento em menos de dois dias deixaram os moradores da região receosos e duvidosos quanto à segurança do mineroduto, prejuízos à saúde e alteração no padrão de vida. O abastecimento de água impactou a população por um período de tempo, além da suspensão de contrato de trabalho de moradores da região com a suspensão da Licença de Operação da empresa. Diante disso, a Tabela 4 apresenta medidas mitigatórias e compensatórias para cada um dos impactos citados acima.

\section{Considerações Finais}

Com a realização do estudo, que buscou responder quais foram os impactos socioambientais causados em decorrência do rompimento do mineroduto na cidade de Santo Antônio do Grama em Minas Gerais, percebeu-se que os impactos ambientais causados pelo projeto sistema Minas-Rio estão muito além dos transtornos causados em decorrência dos episódios de rompimento e projeção de polpa de minério de ferro no ribeirão Santo Antônio ocorridos em março de 2018.

Fez-se necessário entender, para o desenvolvimento do trabalho: o processo de licenciamento ambiental, a amplitude do projeto Minas-Rio como um todo, a dinâmica envolvida no licenciamento do projeto em questão, além da veiculação das informações sobre as ocorrências registradas no município mineiro de Santo Antônio do Grama.

Percebe-se que, o sistema Minas-Rio é controverso desde sua concepção em 2006. E que houve um interesse incomum por parte dos estados do Rio de Janeiro e de Minas Gerais pelo empreendimento, focando somente nos aspectos econômicos. Os estados chegaram a classificar o projeto como de utilidade pública para justificar a supressão vegetal em área de Mata Atlântica, bem como autorizar a desapropriação de 1.121 propriedades em 32 municípios para viabilizar o projeto.

Constatou-se ainda que, mesmo o MPF julgando incipientes as contrapartidas assumidas pela mineradora, o Ibama liberou a LO com validade para sete anos de operação. E que, em menos de quatro anos de atividade, houve duas ocorrências de rompimento com projeção de polpa de minério em cursos d'agua.

As ocorrências foram amplamente divulgadas nos meios de comunicação na data de ocorrência dos rompimentos (dias 12 e 29 de março de 2018), contudo, há falta de divulgação dos impactos socioambientais causados no município e as ações tomadas para mitigação dos efeitos. 
O trabalho trouxe luz à importância do licenciamento ambiental para empresas extrativas, nesse caso bem fundamentado. No âmbito social denuncia, que inevitavelmente o desenvolvimento econômico sobressaiu-se aos direitos ambientais e pessoais, como a desapropriação de terras particulares. Dada a relevância dessas questões frente aos desafios ambientais atuais e futuros, sugere-se a continuidade de trabalhos científicos que valorizem a temática e contribuam com o desenvolvimento sustentável.

\section{Referências}

Anglo American (2008). Quem Somos. http://brasil.angloamerican.com/quem-somos/o-que-fazemos?sc_lang=pt-PT/.

Anglo American (2015). Folder Minas-Rio. https://brasil.angloamerican.com/ /media/Files/A/Anglo-American-Group/Brazil/imprensa/fact-sheets/folderminas-rio-agosto-de-2015.pdf.

ANM. (2018). Informe Mineral. Agencia Nacional de Mineração - ANM. http://www.anm.gov.br/dnpm/publicacoes/serie-estatisticas-e-economiamineral/informe-mineral.

Borges, J. B. (2018). Minas-Rio e água virtual: a luta pelo direito à água em Conceição do Mato Dentro-MG. Dissertação (Mestrado em Políticas Sociais). Campos dos Goytacazes: Universidade Estadual do Norte Fluminense Darcy Ribeiro, 111p.

Brasil (2012). Resoluções do CONAMA: Resoluções vigentes publicadas entre setembro de 1984 e janeiro de 2012. Conselho Nacional do Meio Ambiente CONAMA. Ministério do Meio Ambiente. MMA.

Brasil (2012). Resolução $n^{\circ} 466$ de 12 de dezembro de 2012. DOU no 12, quinta-feira, 13 de junho de 2013, Seção 1, Página 59. Brasília: Conselho Nacional de Saúde.

Carvalho, P. S. L., Silva, M. M., Rocio, M. A. R. \& Moszkowicz, J. (2013). Insumos Básicos: Minério de Ferro. BNDES Setorial, n³9, p. 197-234. https://web.bndes.gov.br/bib/jspui/bitstream/1408/4802/1/BS\%2039\%20min\%C3\%A9rio\%20de\%20ferro_P.pdf

Cervo, A. L., Silva, R. \& Bervian, P. A. (2012). Metodologia Científica. (8a ed.), Pearson Prentice Hall.

CETEM (2016). Implantação do mineroduto Minas-Rio provoca impactos econômicos e socioambientais em 32 municípios mineiros e fluminenses. http://verbetes.cetem.gov.br/verbetes/ExibeVerbete.aspx?verid=112.

Costa, H. A. (2016). Impactos Ambientais Causados em Decorrência do Rompimento da Barragem de Fundão no Município de Mariana-MG na Perspectiva da Mídia Nacional. Trabalho de Conclusão de Curso (Graduação em Ciências Biológicas). Campina Grande: Universidade Estadual da Paraíba. 60 p.

Estado de Minas (2018). Semad determina série de medidas à Anglo American por rompimento de mineroduto. https://www.em.com.br/app/noticia/gerais/2018/03/15/interna_gerais,944471/semad-determina-serie-de-medidas-a-anglo-american-por-rompimento-demi.shtml.

Ferreira, R. S. (2020). A importância do direito ambiental para o desenvolvimento sustentável e a preservação do meio ambiente. Research Society and Development, 9(7):194972591. DOI:10.33448/rsd-v9i7.2591

FIRJAN (2004). Manual de Licenciamento Ambiental: guia de procedimento passo a passo. Federação das Indústrias do Rio de Janeiro - FIRJAN. GMA.

Gil, A. C. (2012). Como elaborar projetos de pesquisa. (6a ed.), Atlas.

G1 MG (2018). Tubulação de mineroduto se rompe em Santo Antônio do Grama, minério atinge ribeirão e abastecimento é interrompido. https://g1.globo.com/mg/minas-gerais/noticia/tubulacao-de-mineroduto-se-rompe-em-santo-antonio-do-grama-na-zona-da-mata.ghtml.

G1 MG (2018). Anglo American diz que segundo rompimento em mineroduto atingiu ribeirão e fazenda em MG. https://g1.globo.com/mg/minasgerais/noticia/anglo-american-diz-que-segundo-rompimento-em-mineroduto-atingiu-ribeirao-e-fazenda-em-mg.ghtml.

IBGE. (2021). Cidades. Instituto Brasileiro de Geografia e Estatística - IBGE. https://cidades.ibge.gov.br/brasil/mg/santo-antonio-do-grama/panorama.

Instituto Minere (2018). Qual a importância da mineração para a economia do país? https://institutominere.com.br/blog/qual-a-importancia-da-mineracaopara-a-economia.

Lakatos, E. M. \& Marconi, M. A. (2012). Metodologia Científica. (7a ed.), Atlas.

Magalhães Júnior, A. P., Carvalho, R. P. B., Facury, D. M., Camilo, G. A. \& Ramanery, G. S. (2020). Minerodutos e implicações socioambientais: Panorama legal e reflexões para o cenário de Minas Gerais. Revista UFMG, 27(3):344-369.

Moreira, A. C. M. L. (1997). Conceitos de Ambiente e de Impacto Ambiental Aplicáveis ao Meio Urbano. Estrato da tese de doutorado intitulada Megaprojetos e Ambiente Urbano: em metodologia para elaboração do Relatório de Impacto de Vizinhança, apresentada a FAU-USP.

PNLA (2019). Estudos Ambientais. Portal nacional de licenciamento ambiental - PNLA. http://pnla.mma.gov.br/estudos-ambientais.

Reis, D. A., Roeser, H. M. P. \& Santiago, A. F. (2019). Impacto ambiental nos sedimentos do tributário do Rio Doce após o rompimento da barragem de Fundão. Research, Society and Development, 9(2): e01921895. 
Research, Society and Development, v. 10, n. 16, e529101623930, 2021

(CC BY 4.0) | ISSN 2525-3409 | DOI: http://dx.doi.org/10.33448/rsd-v10i16.23930

Rodrigues, A. C. M., Silveira, S.F. R., Abrantes, L. A. \& Ferreira, M. A. M. (2008). Análise dos Indicadores Socioeconômicos dos Municípios Mineradores e Não Mineradores do Estado de Minas Gerais. Revista de Ciências Humanas, 8(1):51-68.

Sánchez, L. E. (1994). Gerenciamento Ambiental e Indústria de Mineração. Revista de administração, 29(1):67-75.

Silveira, R. L. (2006). Avaliação dos métodos de levantamento do meio biológico terrestre em estudos de impacto ambiental para a construção de usinas hidrelétricas na região do Cerrado. Dissertação (Mestrado). Piracicaba: Escola Superior de Agricultura Luiz de Queiroz - Universidade de São Paulo.

Souza, A. P. B., Pedrosa, A. S., Pinheiro, I. F. S. \& Santos, M. L. S. (2010). Avaliação de Impactos Ambientais Através de Percepção de Trabalhadores de um Empresa Mineradora: Um Estudo de Caso no Município de Pedra Lavrada - PB. Qualit@s Revista Eletrônica. 9(2). Apud Costa, H. A. (2016). Impactos Ambientais Causados em Decorrência do Rompimento da Barragem de Fundão no Município de Mariana-MG na Perspectiva da Mídia Nacional. Trabalho de Conclusão de Curso (Graduação em Ciências Biológicas). Campina Grande: Universidade Estadual da Paraíba. 60 p. 